\title{
A new synthesis of pyrrolo[1,2-c]quinazoline from quinazolinium $N$-ylides: a re-investigation
}

\author{
Emilian Georgescu, ${ }^{\text {a }}$ Florentina Georgescu, ${ }^{a}$ Mino R. Caira, ${ }^{b}$ Alina Nicolescu, ${ }^{\text {c,d }}$ Calin \\ Deleanu, ${ }^{\mathrm{c}}$ Mariana G. Danila, ${ }^{\mathrm{c}}$ Petru Filip, ${ }^{\mathrm{c}}$ and Florea Dumitrascu*c \\ ${ }^{a}$ Research Centre Oltchim, Uzinei 1, 240050 Ramnicu Valcea, Romania, \\ ${ }^{b}$ Department of Chemistry, University of Cape Town, Rondebosch 7701, South Africa \\ ${ }^{c}$ Centre for Organic Chemistry C.D. Nenitescu, Romanian Academy, 202 B Spl. Independentei, \\ 060023, Bucharest, Romania \\ ${ }^{d}$ P. Poni Institute of Macromolecular Chemistry, Group of Biospectroscopy, Aleea Grigore \\ Ghica 41-A, 700487 Iasi, Romania \\ E-mail:fdumitra@yahoo.com
}

\begin{abstract}
The structure of the products obtained when generating quinazolinium-3-methylides in the absence of an activated alkyne has been investigated using X-ray diffraction and NOE experiments in high resolution NMR. All data are in agreement with a pyrrolo[1,2-c]quinazoline structure having aromatic and benzoyl substituents in positions 2 and 3 respectively, and a hydrogen in position 1 , in contrast to previous assignments with hydrogen in position 3 .
\end{abstract}

Keywords: Quinazolinium-3-methylides, pyrrolo[1,2-c]quinazoline, NOE experiments

\section{Introduction}

Structural similarity to natural products exhibiting useful biological activity prompted the extensive investigation of synthesis, physicochemical and biological properties of $N$-bridgehead heterocyclic compounds. ${ }^{\text {a-g }}$ In our previous studies, ${ }^{2 \mathrm{a}-\mathrm{g}}$ we have reported new $N$-bridgehead heterocyclic compounds obtained via 1,3-dipolar cycloadditions of the corresponding cycloimmonium-ylides with activated alkynes. It is well known that 1,3-dipolar cycloaddition reactions, conducted in a sequential manner, are efficient approaches for the synthesis of new heterocyclic compounds, which are difficult to obtain otherwise. ${ }^{3 a-d}$ The "classical" route to generate cycloimmonium-ylides includes the synthesis of intermediate quaternary salts by heating $N$-heteroaromatic compounds with $\alpha$-halo carbonyl derivatives in chloroform or methanol and treatment of these intermediates with triethylamine or sodium hydroxide, in an appropriate solvent. ${ }^{3 a, 4}$ 
Synthesis of pyrrolo[1,2-c] quinazoline derivatives has been an important topic for our group. ${ }^{5-7}$ These derivatives have been synthesized in methanol by reacting the corresponding quinazolines with $\alpha$-bromocarbonyl compounds followed by direct reaction of the intermediate quinazolinium salts 2 with electron-deficient alkynes in the presence of an epoxide as reaction solvent and acid scavenger. The reaction mechanism implies the in situ generation of quinazolinium-3-methylides and the dipolar addition of the activated alkynes, leading directly to pyrrolo[1,2-c] quinazoline derivatives.

When we tried to isolate intermediate quinazolinium-3-methylides by performing the reactions in the absence of alkynes, we obtained instead pyrrolo[1,2-c]quinazolines. The same compounds were isolated as side products in the "classical" synthesis of pyrrolo[1,2c] quinazoline derivatives by treating the corresponding quaternary salts 2 with activated alkynes or alkenes in the presence of triethylamine as acid acceptor. We obtained the same products also by heating the intermediate quinazolinium salts in benzene in the presence of an equimolar amount of triethylamine. Based on chemical and spectral data, we have assigned to all these compounds a 1,2-disubtituted pyrrolo[1,2-c]quinazoline 1a-h ${ }^{6,7}$ structure (Scheme 1).

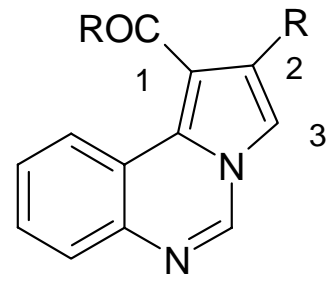

1a-h

a: $\mathrm{R}=\mathrm{C}_{6} \mathrm{H}_{5} ; \mathbf{b}: \mathrm{R}=4-\mathrm{MeOC}_{6} \mathrm{H}_{4} ; \mathbf{c}: \mathrm{R}=4-\mathrm{FC}_{6} \mathrm{H}_{4} ; \mathbf{d}: \mathrm{R}=4-\mathrm{ClC}_{6} \mathrm{H}_{4} ; \mathbf{e}: \mathrm{R}=4-\mathrm{BrC}_{6} \mathrm{H}_{4} ; \mathbf{f}: \mathrm{R}=4-\mathrm{NO}_{2} \mathrm{C}_{6} \mathrm{H}_{4}$; g: $\mathrm{R}=4-\mathrm{NCC}_{6} \mathrm{H}_{4} ; \mathbf{h}: \mathrm{R}=2$-thienyl

\section{Scheme 1}

We have explained the formation of these compounds as the result of an inactivation process of the intermediate quinazolinium-3-methylide. ${ }^{6}$

Two types of inactivation reactions are known for cycloimmonium-ylides. ${ }^{3 a}$ Both are in fact simple dimerization processes. The first one is a simple [3+3] cycloaddition reaction of two molecules of cycloimmonium-ylides as 1,3-dipoles leading to pyrazine derivatives, ${ }^{8-12}$ sometimes reversible. ${ }^{8,10}$ The second one implies carbene intermediates and leads to dimers with an ethylene double bond. ${ }^{3 a, 13}$

While extending our work on the synthesis of pyrrolo[1,2-c]quinazolines of this type, we obtained the new inactivation compounds $\mathbf{3 i}, \mathbf{j}$ by heating the corresponding quinazolinium salts in 1,2-epoxybutane (Scheme 2). Single crystal X-ray analysis of compound $3 \mathbf{i}$ revealed that the benzoyl group is located in position 3 , not in position 1 as in previously reported structures. ${ }^{6,7}$ 
<smiles>O=C([O-])C[n+]1cnc2ccccc2c1</smiles>

2a-j

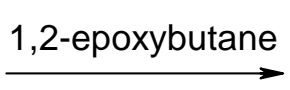<smiles>[R]Cc1c([R])cc2c3ccccc3ncn12</smiles>

3a-j

a: $\mathrm{R}=\mathrm{C}_{6} \mathrm{H}_{5} ; \mathbf{b}: \mathrm{R}=4-\mathrm{MeOC}_{6} \mathrm{H}_{4} ; \mathbf{c}: \mathrm{R}=4-\mathrm{FC}_{6} \mathrm{H}_{4} ; \mathbf{d}: \mathrm{R}=4-\mathrm{ClC}_{6} \mathrm{H}_{4} ; \mathbf{e}: \mathrm{R}=4-\mathrm{BrC}_{6} \mathrm{H}_{4} ; \mathbf{f}: \mathrm{R}=4-\mathrm{NO}_{2} \mathrm{C}_{6} \mathrm{H}_{4}$;

g: $\mathrm{R}=4-\mathrm{NCC}_{6} \mathrm{H}_{4} ; \mathbf{h}: \mathrm{R}=2$-thienyl; $\mathbf{i}: \mathrm{R}=3-\mathrm{MeOC}_{6} \mathrm{H}_{4} ; \mathrm{j}: \mathrm{R}=2$-naphthyl;

Scheme 2. Pyrrolo[1,2-c]quinazoline derivatives.

Based on this evidence, we felt that a re-examination of the structural assignments of the 1a-h compounds using advanced NMR techniques was imperative. Herein we report the revised structures of these inactivation compounds based on NOE experiments. The correct structures are 3a-h instead of 1a-h (Scheme 2).

\section{Results and Discussion}

The X-ray structure of the compound $3 \mathbf{i}^{14-16}$ (Figure 1) exemplifies the 2,3-substitution pattern referred to above. As the pyrrolo[1,2-c] quinazoline system is relatively uncommon, pertinent molecular parameters are summarised here (see also selected bond lengths, Figure 1).

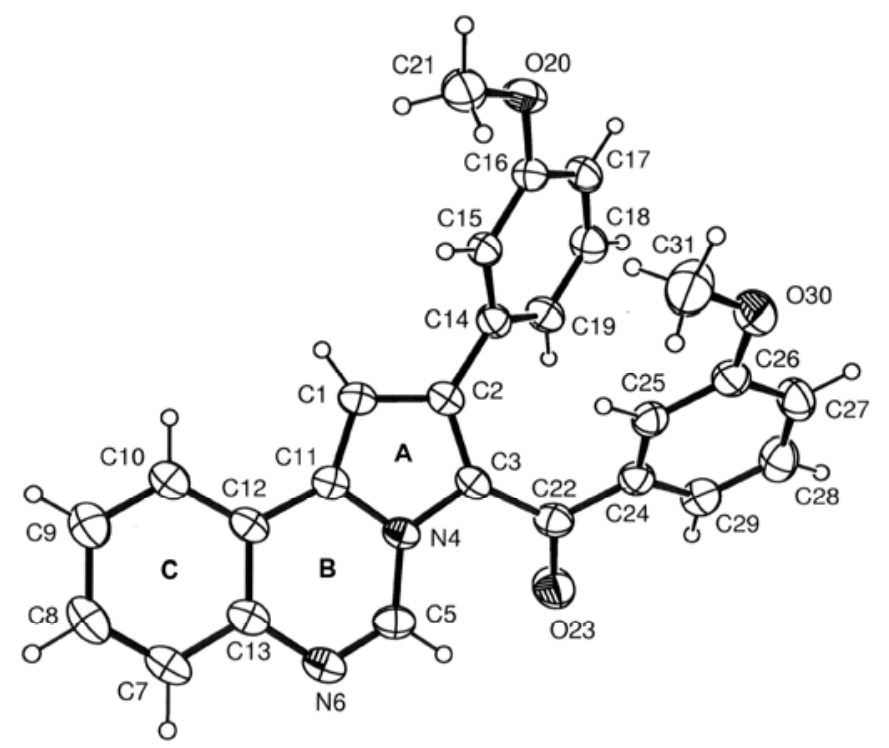

Figure 1. ORTEP plot of $3 \mathbf{i}$ with thermal ellipsoids drawn at the $50 \%$ probability level. Selected bond lengths ( $\AA$, all e.s.d.s $0.002 \AA)$ in the tricyclic system: C1-C2 1.413, C2-C3 1.400, C3-N4 1.403, N4-C11 1.390, C1-C11 1.374, N4-C5 1.387, C5-N6 1.282, N6-C13 1.402. 
A check of the planarity of the 13-membered tricyclic system showed that it is slightly bowed, with interplanar angles $\mathrm{A}^{\wedge} \mathrm{B} 3.4(1)^{\circ}, \mathrm{B}^{\wedge} \mathrm{C} 1.9(1)^{\circ}$ and $\mathrm{A}^{\wedge} \mathrm{C} 5.2(1)^{\circ}$. An intramolecular

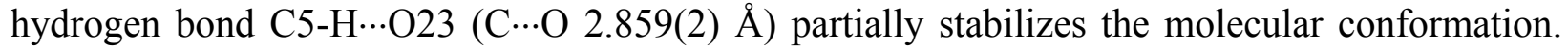
Steric interactions between the bulky substituents attached to $\mathrm{C} 2$ and $\mathrm{C} 3$ are minimised by their rotations around the respective bonds $\mathrm{C} 2-\mathrm{C} 14$ and $\mathrm{C} 22-\mathrm{C} 24$. The torsion angles describing the phenyl ring inclinations relative to the tricyclic mean plane are $\mathrm{C} 3-\mathrm{C} 2-\mathrm{C} 14-\mathrm{C} 19,43.5(2)^{\circ}$ and C3-C22-C24-C25, 26.3(2) ${ }^{\circ}$ respectively. Values for the molecular parameters of the tricyclic system in 3i compare very favourably with those in ethyl 3-(4-chlorobenzoyl)pyrrolo[1,2c] quinazoline-1-carboxylate (i.e. with 1,3-substitution pattern) whose structure we reported recently. ${ }^{17}$

Taking into account the data obtained from X-ray analysis of compound 3i, we decided to reexamine the structural assignments of the inactivation compounds obtained from quinazolinium3-methylides by NMR techniques. Using high resolution NMR we have carefully investigated compounds $\mathbf{3 a}, \mathbf{3 e}, \mathbf{3 f}, \mathbf{3 i}$ and $\mathbf{3} \mathbf{j}$ in order to find support for assigning unambiguously the structures for which X-ray data were not available.

In order to assign the position of the hydrogen atom in the five-membered ring of compounds 3, nuclear Overhauser effects (NOE) have been used to establish a space proximity relation between this proton and those in positions 10 and 5 of the quinazoline ring system. Also the discriminating power of the experiment had to be tested.

On irradiation of proton $\mathrm{H}-10$ the NOE induced the enhancement of the H-1 and H-9 signals. When irradiating proton $\mathrm{H}-1$, the only NOE result is the enhancement of the H-10 signal. On the other hand, irradiation of the $\mathrm{H}-5$ proton has no effect on the $\mathrm{H}$ signal assigned as $\mathrm{H}-1$. This lack of effect proves that the proton is not attached to the position 3 of the heterocycle and the overall experimental results allow the unambiguous assignment of benzoyl in position 3 and $\mathrm{H}$ in position 1 for all investigated compounds.

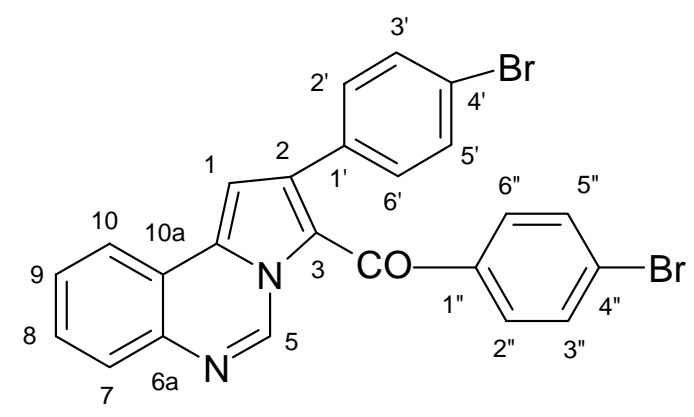

$3 e$

The NOE arguments described above are exemplified below for the case of the compound 3e. The ${ }^{1} \mathrm{H}-\mathrm{NMR}$ spectrum (Figure $2 \mathrm{a}$ ) shows distinct signals for all protons of interest: H-5 resonates at 10.05 ppm, $\mathrm{H}-10$ at $8.10 \mathrm{ppm}, \mathrm{H}-9$ at $7.65 \mathrm{ppm}, \mathrm{H}-1$ at $7.11 \mathrm{ppm}$ and $\mathrm{H}-2^{\prime} / 6^{\prime}$ at 7.01 ppm. 
Irradiation of proton H-10 leads to NOE enhancements for protons H-9 and H-1 (Figure 2b). This strongly suggests that the hydrogen atom is linked to position 1 of the heterocycle. Irradiation of proton H-1 leads to NOE enhancement for signal H-10 (Figure 2c), confirming the result of the previous NOE experiment. Irradiation of proton $\mathrm{H}-5$ produces no effects in the spectrum (Figure 2e).

The lack of NOE effects on irradiation of the H-5 proton supports a structure with no proton attached at position 3 of the heterocycle. One should note that there is an artefact in the spectrum presented in Figure $2 \mathrm{~d}$ around $7.26 \mathrm{ppm}$. This artifact is due to the residual solvent peak $\left(\mathrm{CHCl}_{3}\right)$ but as can be seen, there is no effect on irradiation on any signal belonging to the analyzed compound. One more experiment is presented in Figure $2 \mathrm{e}$ as proof of the quality of the NOE experiments. In this experiment, irradiation of the H-2\% 6 ' protons leads to NOE enhancement of the H-3'/5' signal. This latter experiment is only presented in order to prove the selectivity of the irradiation. In this experiment it is clear that the selectivity of the irradiation of the signal at 7.01 ppm (H-2'/6') is very good and does not affect the signal at $7.11 \mathrm{ppm}(\mathrm{H}-1)$. This latest experimental check supports the fact that the irradiation of the $\mathrm{H}-1$ proton from the experiment presented in Figure 2c also produces selective NOE effects in the NMR spectrum.

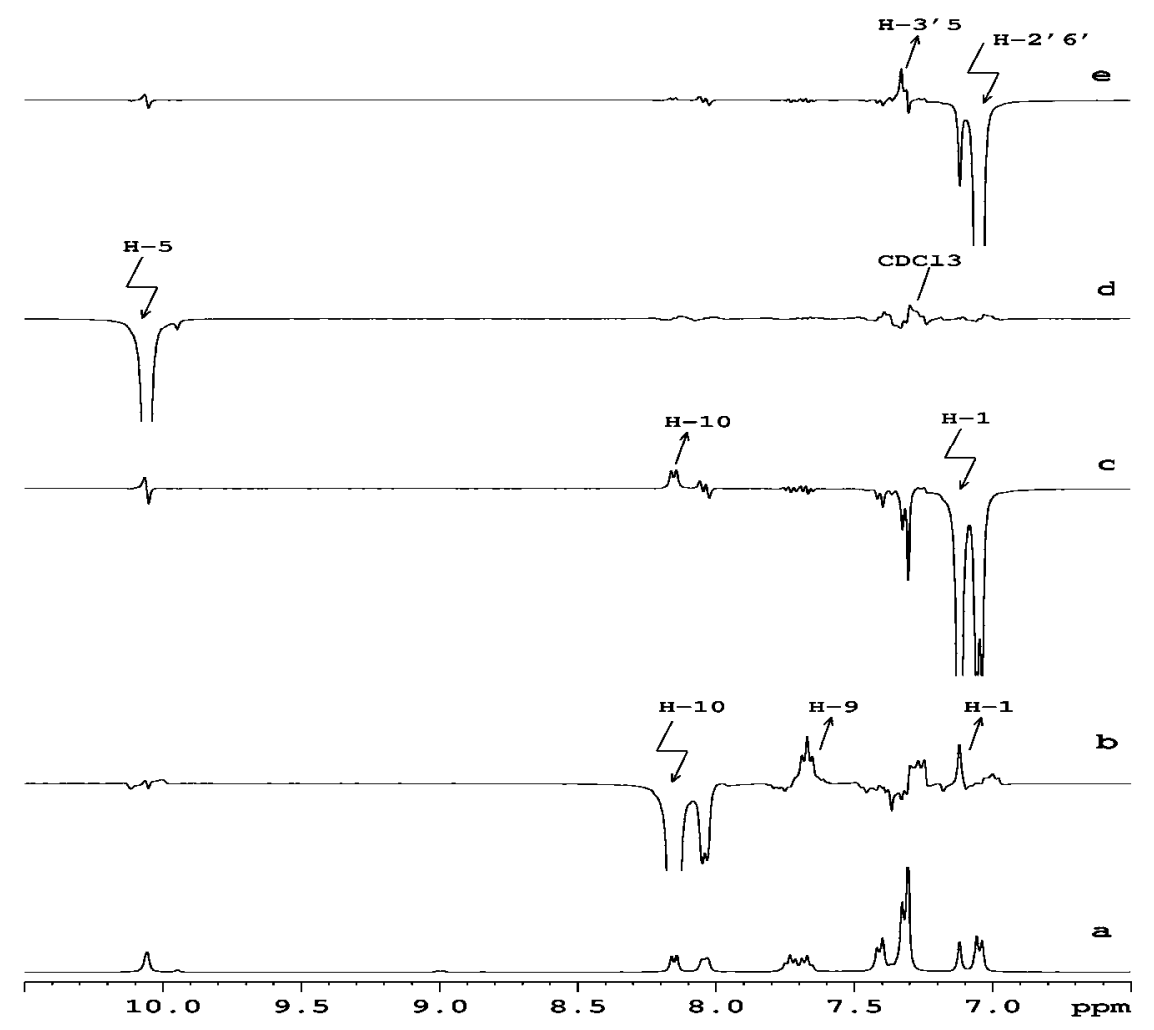

Figure 2. NOE differential experiments for compound 3e. The ${ }^{1} \mathrm{H}-\mathrm{NMR}$ spectrum (2a). Irradiation of proton $\mathrm{H}-10$ (2b). Irradiation of $\mathrm{H}-1$ (2c). Irradiation of proton $\mathrm{H}-5$ (2d). Irradiation of the H-2'/6' (2e). 
The NOE behaviour also holds true for compound 3i. The most relevant proof for ring substitution is the same through space interaction between protons $\mathrm{H}-10$ and $\mathrm{H}-1$. Figure 3 presents the irradiation of proton $\mathrm{H}-10$ leading to NOE enhancements for protons $\mathrm{H}-1$ and $\mathrm{H}-9$.

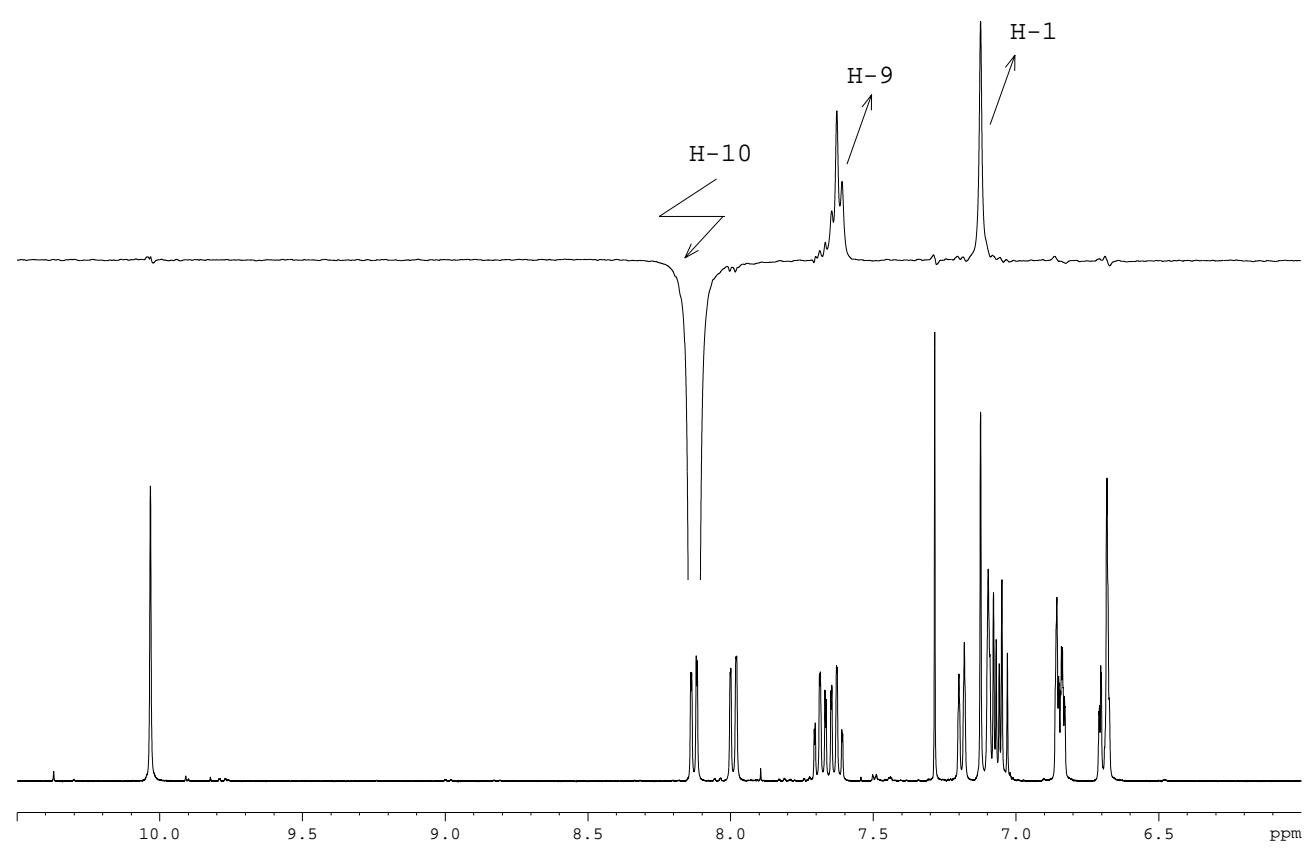

Figure 3. NOE differential experiments for compound 3i. The ${ }^{1} \mathrm{H}-\mathrm{NMR}$ spectrum (bottom). Irradiation of proton $\mathrm{H}-10$ (top).

The reaction mechanism probably involves a nucleophilic attack of the ylide carbanion on the carbon atom at the 4 position of the quinazolinium-3-methylide with the elimination of one equivalent of quinazoline (Scheme 3).

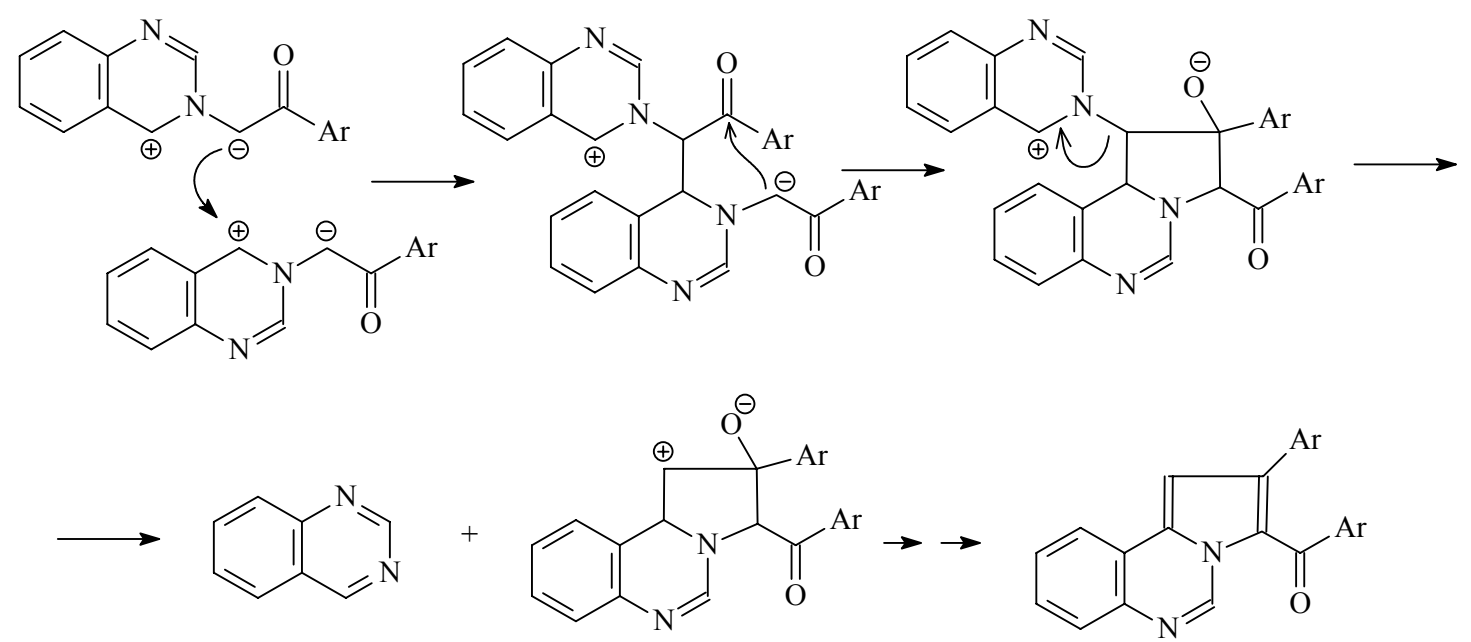

Scheme 3. Reaction mechanism 


\section{Conclusions}

The structures of inactivation products of quinazolinium-3-methylides have been investigated using X-ray diffraction and NOE experiments in high resolution NMR. All data are in agreement with a pyrrolo[1,2-c]quinazoline structure having substituents in positions 2 and 3 and a hydrogen in position 1, in contrast with previous data assigning hydrogen in position 3 .

\section{Acknowledgements}

MRC thanks the University of Cape Town and the NRF for financial support.

\section{Experimental Section}

General Procedures. Compounds $3 \mathbf{i}$ and $3 \mathbf{j}$ were synthesized according to the procedure reported previously. ${ }^{6,7}$ Melting points were determined on a Boetius apparatus and are uncorrected. The IR spectra (in $\mathrm{KBr}$ ) were recorded on a Nicolet Impact 410 spectrometer. The ${ }^{1} \mathrm{H}$ - and ${ }^{13} \mathrm{C}$-NMR spectra were recorded at room temperature on a Bruker Avance DRX 400 spectrometer operating at $400.13 \mathrm{MHz}$ for ${ }^{1} \mathrm{H}$ and $100.61 \mathrm{MHz}$ for ${ }^{13} \mathrm{C}$ nuclei using TMS as internal standard. The NOE differential spectra (NOEDIFF) were recorded on degassed solutions by cycling the frequency on at least 3 points on each irradiated signal. Elemental analyses were determined on COSTECH Instruments EAS32 (Centre for Organic Chemistry, Spl. Independentei 202B, Bucharest 060023, Romania). Satisfactory microanalyses for all new compounds were obtained.

Quinazoline, 2-bromo-2'-acetonaphthone, 2-bromo-3'-methoxyacetophenone and 1,2epoxybutane are commercially available products (Aldrich).

Melting points, yields, IR spectra and elemental analyses for compounds 3a, 3e and $\mathbf{3 f}$ have been presented previously. ${ }^{6,7}$

3-Benzoyl-2-phenylpyrrolo[1,2-c]quinazoline (3a). ${ }^{1} \mathrm{H}-\mathrm{NMR}\left(400, \mathrm{CDCl}_{3}\right)$ 8: 7.02-7.10 $(5 \mathrm{H}$, m, H-3', H-4', H-5', H-3”, H-5'), 7.07 (1H, d, J 0.5 Hz, H-1), 7.13-7.17 (2H, m, H-2', H-6'), 7.23 (1H, tt, $J$ 7.5, $1.5 \mathrm{~Hz}, \mathrm{H}-4$ "), 7.53 (2H, dd, $J$ 8.3, $1.3 \mathrm{~Hz}, \mathrm{H}-2$ ", H-6"), 7.55 (1H, td, $J$ 7.9, $1.5 \mathrm{~Hz}, \mathrm{H}-8), 7.59(1 \mathrm{H}, \mathrm{td}, J 7.9,1.5 \mathrm{~Hz}, \mathrm{H}-9), 7.95(1 \mathrm{H}, \mathrm{dd}, J 7.8,1.5 \mathrm{~Hz}, \mathrm{H}-7), 8.09$ (1H, dd, $J$ 7.9, $1.5 \mathrm{~Hz}, \mathrm{H}-10), 10.00$ (1H, bs, H-5). ${ }^{13} \mathrm{C}-\mathrm{NMR}\left(100 \mathrm{MHz}, \mathrm{CDCl}_{3}\right) \delta: 103.67$ (CH-1), 120.09 (C-10a), 122.88 (C-3, CH-10), 127.35 (CH-4'), 127.65, 127.87 (CH-3', CH-5', CH-3”, CH-5”), 128.20 (CH-9), 128.48 (CH-7), 129.59 (CH-8), 129.76 (CH-2", CH-6"), 130.05 (CH-2', CH-6'), 134.02 (C-10b), 135.10 (C-1'), 138.67 (C-1"), 138.82 (CH-5), 139.41 (C-6a), 139.80 (C-2), $187.52(\mathrm{CO})$.

3-(4-Bromobenzoyl)-2-(4-bromophenyl)pyrrolo[1,2-c]quinazoline (3e). ${ }^{1} \mathrm{H}-\mathrm{NMR}$ (400 MHz, $\left.\mathrm{CDCl}_{3}\right) \delta: 7.01(2 \mathrm{H}, \mathrm{d}, J 8.4 \mathrm{~Hz}, \mathrm{H}-2$ ', H-6'), $7.11(1 \mathrm{H}, \mathrm{d}, J 0.8 \mathrm{~Hz}, \mathrm{H}-1), 7.27(4 \mathrm{H}, \mathrm{d}, J 8.4 \mathrm{~Hz}$, 
H-3', H-5', H-3”, H-5”), 7.36 (2H, d, J 8.6 Hz, H-2”, H-6”), 7.65 (1H, td, J 7.8, 1.5 Hz, H-9), $7.68(1 \mathrm{H}, \mathrm{td}, J 8.0,1.5 \mathrm{~Hz}, \mathrm{H}-8), 7.96(1 \mathrm{H}, \mathrm{dd}, J 8.0,1.5 \mathrm{~Hz}, \mathrm{H}-7), 8.10(1 \mathrm{H}, \mathrm{dd}, J 7.8,1.5 \mathrm{~Hz}$, $\mathrm{H}-10), 10.05$ (1H, bs, H-5). ${ }^{13} \mathrm{C}-\mathrm{NMR}\left(100 \mathrm{MHz}, \mathrm{CDCl}_{3}\right) \delta: 103.55$ (CH-1), 119.89 (CH-10a), 121.14 (C-3), 122.14 (C-4'), 122.94 (CH-10), 126.95 (C-4”), 128.43 (CH-9), 128.62 (CH-7), 129.95 (CH-8), 131.13 (CH-2”, CH-6”), 131.09, 131.23 (CH-3', CH-5', CH-3”, CH-5”,), 131.45 (CH-2', CH-6'), 137.40 (C-1'), 133.49 (C-1'), 134.51 (C-10b), 138.54 (CH-5), 138.57 (C-2), 139.51 (C-6a), 185.97 (CO).

3-(4-Nitrobenzoyl)-2-(4-nitrophenyl)pyrrolo[1,2-c]quinazoline (3f). ${ }^{1} \mathrm{H}-\mathrm{NMR}$ (400 $\mathrm{MHz}$, $\mathrm{CDCl}_{3}$ +TFA) $\delta$ : 7.41 (2H, d, J $8.8 \mathrm{~Hz}, \mathrm{H}-2^{\prime}, \mathrm{H}-6$ '), 7.45 (1H, bs, H-1), 7.69 (2H, d, $8.8 \mathrm{~Hz}, \mathrm{H}-$ 2", H-6”), 7.90-7.98 (2H, m, H-8, H-9), 8.01 (2H, d, 8.8 Hz, H-3”, H-5”), 8.06 (2H, d, J 8.8 Hz, H-3', H-5'), 8.13-8.20 (1H, m, H-7), 8.27-8.34 (1H, m, H-10), 10.79 (1H, bs, H-5). ${ }^{13} \mathrm{C}-\mathrm{NMR}$ (100 MHz, $\left.\mathrm{CDCl}_{3}+\mathrm{TFA}\right) \delta: 107.42$ (CH-1), 118.76 (C-3), 122.50 (CH-7), 122.86 (C-10a), 123.43 (CH-3", CH-5”), 123.77 (CH-3', CH-5'), 124.02 (CH-10), 130.36 (C-6a), 130.63 (CH2", CH-6”), 130.91 (CH-2', CH-6'), 131.85 (CH-9), 132.68 (CH-8), 133.74 (C-10b), 138.71 (C1'), 141.51 (C-2), 141.93 (C-1”), 142.61 (CH-5), 147.92 (C-4'), 149.99 (C-4”), 185.11 (CO).

3-(3-Methoxybenzoyl)-2-(3-methoxyphenyl)pyrrolo[1,2-c]quinazoline (3i). Yellow crystals mp 169-170 ${ }^{\circ} \mathrm{C}$, yield 27\%; IR (KBr, cm $\left.{ }^{-1}\right): 1609\left(v_{\mathrm{CO}}\right) .{ }^{1} \mathrm{H}-\mathrm{NMR}\left(400 \mathrm{MHz}, \mathrm{CDCl}_{3}\right) \delta: 3.64$ (3H, s, OMe-3'), 3.66 (3H, s, OMe-3’), 6.60-6.70 (1H, m, H-4'), 6.67 (1H, s, H-2'), 6.80-6.85 (2H, m, H-6', H-4”), 7.03 (1H, t, J 7.7 Hz, H-5”), 7.03-7.09 (1H, m, H-5'), 7.07 (1H, s, H-2”), $7.10(1 \mathrm{H}, \mathrm{d}, J 0.7 \mathrm{~Hz}, \mathrm{H}-1), 7.17$ (1H, dt, J 7.7, $1.3 \mathrm{~Hz}, \mathrm{H}-6 ”), 7.60$ (1H, td, J 7.6, $1.4 \mathrm{~Hz}, \mathrm{H}-9$ ), $7.66(1 \mathrm{H}, \mathrm{td}, J 7.8,1.5 \mathrm{~Hz}, \mathrm{H}-8), 7.97(1 \mathrm{H}, \mathrm{dd}, J 7.8,1.5 \mathrm{~Hz}, \mathrm{H}-7), 8.10(1 \mathrm{H}, \mathrm{dd}, J 7.6,1.4 \mathrm{~Hz}$, $\mathrm{H}-10), 10.02$ (1H, bs, H-5). ${ }^{13} \mathrm{C}-\mathrm{NMR}\left(100 \mathrm{MHz}, \mathrm{CDCl}_{3}+\mathrm{TFA}\right) \delta:$ 55.15, 55.25 (OMe-3', OMe3”), 103.80 (CH-1), 113.75 (CH-4'), 113.94 (CH-2”), 115.33 (CH-2'), 118.76 (CH-4”), 120.06 (C-10a), 121.52 (C-3), 122.34 (CH-6'), 122.42 (CH-6”), 122.91 (CH-10), 128.32 (CH-9), 128.33 (CH-7), 128.85 (CH-5”), 129.04 (CH-5'), 129.71 (CH-8), 134.02 (C-10b), 136.06 (C-1'), 138.92 (CH-5), 139.14 (C-6a), 139.77 (C-2), 140.09 (C-1”), 159.00, 159.05 (C-3', C-3”), 187.16 (CO). Calcd. for $\mathrm{C}_{26} \mathrm{H}_{20} \mathrm{~N}_{2} \mathrm{O}_{3}$ : C 76.5, H 4.94, N 6.86. Found: C 76.31, H 4.80, N 6.88.

3-(2-Naphthoyl)-2-(2-naphthyl)pyrrolo[1,2-c]quinazoline (3j). Yellow crystals, mp 230$231{ }^{\circ} \mathrm{C}$, yield 31\%; IR $\left(\mathrm{KBr}, \mathrm{cm}^{-1}\right): 1607\left(v_{\mathrm{CO}}\right) .{ }^{1} \mathrm{H}-\mathrm{NMR}\left(400 \mathrm{MHz}, \mathrm{CDCl}_{3}\right)$ 8: $7.22(1 \mathrm{H}, \mathrm{d}, J 0.7$ $\mathrm{Hz}, \mathrm{H}-1), 10.07$ (1H, bs, H-5), 7.97 (1H, dd, 7.9, $1.3 \mathrm{~Hz}, \mathrm{H}-7), 7.63-7.71(1 \mathrm{H}, \mathrm{m}, \mathrm{H}-8), 7.62(1 \mathrm{H}$, td, 7.7, 1.6 Hz, H-9), 8.14 (1H, dd, 7.7, 1.6, H-10), 8.02 (1H, d, 1.7 Hz, H-1”), 7.70 (1H, m, H3'), 7.12-7.58 (12H, m, H-1', H-3', H-4', H-5', H-6', H-7', H-8', H-4”, H-5', H-6”, H-7’, H-8’). ${ }^{13} \mathrm{C}-\mathrm{NMR}\left(100 \mathrm{MHz}, \mathrm{CDCl}_{3}\right) \delta: 103.84$ (CH-1), 120.15 (C-10a), 121.96 (C-3), 122.93 (CH-10), 128.54 (CH-9), 128.71 (CH-7), 129.11, (CH-3”), 129.64 (CH-8), 131.67 (CH-1”), 134.11 (C10b), 138.88 (CH-5), 139.46 (C-6a), 139.78 (C-2), 187.43 (CO), 134.61, 135.73 (C-2”, C-4a”), 131.79, 132.02, 132.75, 132.76 (C-4a', C-8a', C-2', C8a”), 127.52, 125.99, 127.48, 127.33, 125.99, 125.12, 127.22, 128.26, 127.68, 127.22, 125.99, 127.61 (CH-1' CH-3', CH-4', CH-5', CH-6', CH-7', CH-8', CH-4", CH-5", CH-6", CH-7”, CH-8"'). Calcd. for $\mathrm{C}_{32} \mathrm{H}_{20} \mathrm{~N}_{2} \mathrm{O}$ : C 85.69, $\mathrm{H}$ 4.49, N 6.15. Found: C 85.50, H 4.38, N 6.17. 


\section{References and Notes}

1. (a) Hermecz, I.; Meszaros M. Adv. Heterocycl. Chem. 1983, 33, 241. (b) Swinbourne, J. F.; Hunt, H. J.; Klinkert, G. Adv. Heterocycl. Chem. 1987, 23, 103. (c) Hermecz, I.; VasvaryDebreczy, L.; Matyus, P. In Comprehensive Heterocyclic Chemistry, Katritzky, A. R.; Rees C. W.; Scriven, E. F. V., Eds.; Pergamon Press: London, 1996; Vol. 8, Ch. 23, pp. 563-595. (d) Granzhan, A.; Ihmels, H. Arkivoc 2007, (viii), 136. (e) Kaur, B.; Kaur, R. Arkivoc 2007, (xv), 315. (f) Kumar, S.; Sahu, D. P, Arkivoc 2008, (xv), 88. (g) Vasko, G. A.; Riedel, Z.; Egyed, O.; Hajos, G. Arkivoc 2008, (iii), 25.

2. (a) Georgescu, E.; Georgescu, F.; Roibu, C.; Draghici, C.; Caproiu, M.T. Rev. Roum. Chim. 2001, 46, 357. (b) Georgescu, E.; Georgescu, F.; Roibu, C.; Iuhas, P. C.; Draghici, C.; Caproiu, M.T. Rev. Roum. Chim. 2002, 47, 885. (c) Georgescu, E.; Georgescu, F.; Danila, M.D.; Filip, P.; Draghici, C.; Caproiu, M. T. Arkivoc 2002, (ii), 30. (d) Georgescu, E.; Draghici, C.; Iuhas, P. C.; Georgescu, F. Arkivoc 2005, (x), 95. (e) Georgescu, E.; Georgescu, F.; Iuhas, P. C.; Draghici, C.; Danila, M. G.; Filip, P. Arkivoc 2007, (x), 381. (f) Mangalagiu, I. I.; Mangalagiu, G.; Deleanu, C.; Drochioiu, G.; Petrovanu, M.; Tetrahedron 2003, 59, 111. (g) Caprosu, M.; Zbancioc, G.; Moldoveanu, C.; Mangalagiu, I. I. Collect. Czech. Chem. Commun. 2004, 39, 426.

3. (a) Zugravescu, I.; Petrovanu, M. (authors) N-Ylides Chemistry, McGraw-Hill Internat. 1976.

(b) Padwa, A. Ed: 1,3-Dipolar Cycloaddition Chemistry, John Wiley \& Sons: New York; Vols. 1 and 2, 1984. (c) Dumitrascu, F.; Dumitrescu, D. G. Arkivoc 2008, (i), 232. (d) Dumitrascu, F.; Caira, M. R.; Vasilescu, M.; Barbu, L.; Dumitrescu, D. G. Arkivoc 2007, (xvi), 101.

4. Krohnke, F. Chem. Ber. 1935, 68, 1177.

5. (a) Georgescu, E.; Druţa, I.; Petrovanu, M. Rev. Roum. Chim., 1981, 26, 109. (b) Georgescu, E.; Druţă, I.; Petrovanu, M. Bul. Inst. Politehnic Iaşi 1981, XXVII (3-4), sect.II, 81. (c) Georgescu, E.; Georgescu, F.; Chiraleu, F.; Petrovanu, M. Rev. Roum. Chim. 1983, $28,841$. (d) Georgescu, F.; Georgescu, E.; Draghici, C.; Caproiu, M. T. Rev. Roum. Chim. 1997, 42, 17. (e) Georgescu, E.; Georgescu, F.; Gheorghiu, M.; Georgescu, E. G.; Petrovanu, M. Rev. Roum. Chim. 1985, 30, 611.

6. Georgescu, E.; Georgescu, F.; Gheorghiu, M.; Filip, P; Petrovanu, M. Rev. Roum. Chim. 1986, 31,365 .

7. Georgescu, E.; Georgescu, F.; Roibu, C.; Iuhas, P. C.; Draghici, C.; Filip, P. Arkivoc 2008, (xii), 60 .

8. Ahlbrecht, H.; Froehlich, J.; Habermalz, U.; Krohnke, F. Tetrahedron Lett. 1967, 8, 3649.

9. Zugravescu, I.; Georgescu, F.; Chiraleu, F.; Filip, P.; Georgescu, E. Rev. Chim. (Bucharest) 1980, 31, 11 .

10. Georgescu, F.; Chiraleu, F.; Georgescu, E.; Zugravescu, I. Rev. Roum. Chim. 1981, $26,879$. 11. Mangalagiu, G. C.; Mangalagiu, I. I.; Olariu, R. I.; Petrovanu, M. G. Synthesis 2000, 2047. 
12. Iuhas, P. C.; Georgescu, E.; Georgescu, F.; Draghici, C.; Caproiu, M. T. Rev. Roum. Chim. 2001, 46, 55.

13. Caprosu, M.; Petrovanu, M.; Druta, I.; Zugravescu, I. Bull. Soc. Chim. Fr. 1971, 1843.

14. Intensity data for the crystal of compound 2a were collected on a Nonius Kappa CCD diffractometer. Structure solution by the direct method (SHELXS-97 ${ }^{15}$ ) and full-matrix leastsquares refinement (SHELXL-97 ${ }^{16}$ ) proceeded routinely. All non-H atoms were treated anisotropically. $\mathrm{H}$ atoms were located in difference Fourier syntheses and were added in idealized positions in a riding model with $U_{H}=1.2-1.5$ times those of the parent atoms. Crystal data for 2a: $\mathrm{C}_{26} \mathrm{H}_{20} \mathrm{~N}_{2} \mathrm{O}_{3}, M=408.44$, yellow blades, specimen dimensions $0.30 \times$ $0.09 \times 0.05 \mathrm{~mm}^{3}$, orthorhombic, space group Pbca (No. 61), $a=7.3942(3), b=20.8950(9), c$ $=25.909$ (1) $\AA, V=4002.9(3) \AA^{3}, Z=8, D_{\mathrm{c}}=1.355 \mathrm{~g} / \mathrm{cm}^{3}, \mu=0.090 \mathrm{~mm}^{-1}, F_{000}=1712$, MoK $\alpha$ radiation, $\lambda=0.71073 \AA, T=173(2) \mathrm{K}, 2 \theta_{\max }=55.0^{\circ}, 24279$ reflections collected, 4565 unique $\left(\mathrm{R}_{\text {int }}=0.0728\right)$. Final $G o o F=1.003, R_{1}=0.0460, w R 2=0.0968, R$ indices based on 2697 reflections with $\mathrm{I}>2 \sigma(\mathrm{I})$ (refinement on $F^{2}$ ), 283 parameters, 0 restraints. Lp corrections applied. CCDC deposition no. 737383.

15. Sheldrick, G. M. SHELXS-97, 1997, University of Göttingen, Germany.

16. Sheldrick, G. M. SHELXL-97, 1997, University of Göttingen, Germany

17. Caira, M. R.; Georgescu, E.; Georgescu, F.; Dumitrascu, F. X-ray Structure Analysis Online 2009, 25,5 . 